\title{
THE SUPPLY OF FOREIGN DIRECT INVESTMENT INCENTIVES: SUBSIDY COMPETITION IN AN OLIGOPOLISTIC FRAMEWORK
}

\author{
Tomáš Havránek*
}

\begin{abstract}
This paper examines the microeconomic motivation of governments to provide tax incentives for foreign direct investment. Author applies the classical models of oligopoly to subsidy competition, endogenousing investment incentives, but leaving tax rates exogenous. According to the conventional wisdom, subsidy competition leads to overprovision of incentives. This paper suggests that, in the oligopolistic framework, supranational coordination can either decrease or increase the supply of subsidies. Further, in the setting of subsidy regulation, the host country's corporate income tax rate has an ambiguous effect on the provision of incentives.
\end{abstract}

Keywords: investment incentives, subsidy competition, productivity spillovers, oligopoly, foreign direct investment, multinational corporations

JEL Classification: F12, F21, F23, H25, H71, H87

\section{Introduction}

In the last decades, a rivalry for foreign direct investment (FDI) has been catching the attention of economists increasingly. With loosening restraints to international trade and growing volumes of FDI since the early 1980s, FDI competition has been progressively escalating; and thus the question of foreign direct investment incentives (INIs) is getting on urgency. In an effort to obtain FDI under their legislation, governments offer extensive support at all levels, capable of granting hundreds of thousands USD per one generated working station. ${ }^{1}$ Supporters of INIs argue that worldwide subsidy competition is a game with a positive outcome - positive externalities linked to FDI are being internalized and the total allocation of investments is said to be more efficient than without INIs. But the majority of economists is rather skeptical toward subsidy competition. They claim that the increase in allocation efficiency is nowise guaranteed; INIs can per contra bring extensive distortions to various markets, and globally a race to the bottom in the form of constantly lower tax revenues and

* Charles University in Prague, Institute of Economic Studies, Opletalova 26, CZ - 11000 Praha 1 (tomas.havranek@ies-prague.org). The author is much indebted to Zuzana Iršová for her valuable suggestions. Great help was provided by Ivo Koubek, Terezie Lokajičková and Radek Bulva as well. The usual caveat applies.

1 See e.g. Brazil incentives for Renault and Mercedes in the 1990s (da Motta Veiga, Iglesias, 1998, p. 59). 
loosening of ecological standards - or impeding socially efficient tightening of these standards, which would follow otherwise - much like a threat to employees' rights. ${ }^{2}$

As all available meta-analyses (Görg, Strobl, 2001; Meyer, Sinani, 2005; Wooster, Diebel, 2006; Havránek, Iršová, 2008) illustrate, there is no persuasive empirical evidence of technological and knowledge diffusion, which - in the form of productivity spillovers - presents the most important theoretical background for the provision of INIs. This holds especially for intra-industry spillovers, while an elaborate empirical analysis of inter-industry spillovers is only at its beginnings. Until a satisfactory resolution of this problem is given, one can hardly draw any relevant conclusions about the efficiency of INIs.

Which aspects affect an offered INI volume the most? To what degree is the international subsidy competition intense? To help with the discussion of such problems, we will present two supply-of-investment-incentives models; the first one for the minimal sufficient INI, the other one for the optimal INI; and we will attempt to integrate them into a more general model.

Most of theoretical works call for some form of global coordination of INIs (see, inter alia, UNCTAD, 1996), hoping that such agreement would decrease the provision of INIs - thus implicitly assuming that free subsidy competition leads to overprovision of FDI incentives. To our knowledge, the first formalized model which shows that this need not be the case is Haufler, Wooton (2006). In the present paper, we support their claim, using a very different, regime-competition model. ${ }^{3}$ It is also shown that higher corporate income tax (CIT) rate does not necessarily increase the optimal subsidy levels, as could be intuitively expected.

The paper is structured as follows: Section 2 provides a survey of related literature; the Minimal Sufficient INI Model (a targeted-competition model) is going to be proposed. Section 3 introduces the Optimal INI Model (a regime-competition model) and lists a few modifications. Section 4 concludes the paper.

\section{The Minimal Sufficient INI Model}

\subsection{Related Work}

There has been a substantial body of literature concerning with formalized modelling of the provision of INIs. Absolute majority of models varies in assumptions rather than in methodology - different premises mean different definitions of corresponding public utility functions. From our perspective, the key precondition is the presence of positive externalities from FDI, i.e. productivity spillovers, because this presumption offers a fundamental line of reasoning for the very existence of subsidy systems. Let us outline the most relevant works:

Haaparanta (1996) postulates that countries maximize wage income of their citizens resulting from working for foreign investors. Incentive schemes upset optimal

2 Oman (2000, p. 20) compares the process to the wave of devaluations and protectionism of the 1930s; issue has a character of the prisoner's dilemma.

3 For an excellent discussion of different types of competition, see OECD (2003). 
investment allocation - in the equilibrium, even countries with relatively high wages can attract investments, although all countries grant optimal INIs from their point of view. Therefore, in comparison to the situation when no one granted subsidies, countries with lower competitiveness can augment the volume of attracted FDI.

In Haaland, Wooton (1999), the entry of a multinational company (MNC) to the local market increases demand for intermediate products made in the host country, which leads to other companies' entry to the imperfect competition market of intermediates. Improved competing background motivates other foreign investors to enter the country, thereby multiplicatively raises national income and social welfare. Governments are aware of these effects - hence they grant INIs in an effort to compete with other countries, awaiting the same benefits.

Barros \& Cabral (2000) study competition between a smaller country with high unemployment rate and a larger country without this problem. They assume that there are no such firms capable of competing with the MNC. In the absence of subsidies, the country with larger domestic market is more attractive but has less motivation to lure the investment. Subsequently, a rivalry by means of incentives could end in locating the investment into the smaller country. The authors argue that incentives can increase total welfare - the smaller country needs the investment more and has a higher benefit from attracting it.

Pennings (2001) presents a two-agent model of a country and a foreign monopolistic producer. The company can choose whether to export its products into the country or to undergo a horizontal FDI. In conclusion, for a country which maximizes public utility an optimal strategy is to compensate investor's expenses fully by incentives and subsequently by taxes to reduce income which exceeds his alternative profit from importing into the country.

Haufler, Wooton (2006) decompose competition between two countries facing the third one simultaneously. They are the first to show that in comparison to "free subsidy competition", coordinated policy of two countries could bring a decrease as well as an increase of offered INIs.

Bjorvatn, Eckel (2006) analyse FDI competition between asymmetric countries, differing both in market size and structure. They consider a presence of domestic firms and show that competition tends to be strong especially when both countries are similar in terms of business conditions. In such cases, countries can provide really significant INIs, and vice versa.

Ma (2007) supposes that inflow of FDI has certain redistribution effects in the domestic economy. He investigates the influence of interest groups on the competition intensity between competing countries. Due to this tension, the winner can be also the country that would not otherwise have a chance to succeed; and the costs of attracting FDI increase for both countries.

Although we got inspired by the aforementioned models, we shall use a different methodology. Our intention is to demonstrate which influences are the most powerful toward the amount of INIs provision - we are interested in their determinants, not in the efficiency of provision. Let us start from the model of Haufler, Wooton (1999) 
and its later application by Sedmihradský (2002). ${ }^{4}$ Firsty, we adjust their model for its consecutive application for the expression of minimal sustainable tax relief.

\subsection{Methodology and Basic Assumptions}

Definition 1. Minimal sustainable tax relief of country $i$ or critical rate of tax relief of country $i$ means the smallest feasible incentive of country $i$ which makes an investor indifferent between the alternatives of countries $i$ and $j(i, j \in\{1,2\})$.

Assumption 1. Let us assume that there are two countries of different size that vary except GDP also in the level of wage costs and corporate income tax (CIT) rate. We think of an MNC producing a sole product. The company faces descending demand curve - to simplify, it is a global monopoly. Let individual demand functions be in the form:

$$
d(q)=\frac{a-q}{b},
$$

where $q$ is price and $a, b$ are respective parameters of the demand.

Assumption 2. Investor's home country does not tax its residents' foreign-earned incomes. Furthermore, there is no transfer pricing within the MNC.

The investor considers investing into a production capacity. Since we do not consider any other markets, the company can choose ideally from these possibilities: $(i)$ to invest in Country 1 and export part of its production to Country 2, (ii) to invest in Country 2 and import into Country 1, (iii) to invest in both countries, or (iv) not to invest at all. If we presume the existence of transaction costs of goods transportation from Country 1 to Country 2 and vice versa (e.g., expenses connected with transport, distribution, marketing, market research, etc.), investor may select the third option.

Assumption 3. Let us assume the prohibitively high fixed costs in respect to the third possibility. Let us suppose also that the company's hypothetical gain would be positive in both countries.

May Country 2 have number of inhabitants equal to m. Suppose that Country 1 has n-times higher GDP than Country 2. Using this proportion as a weight, let us postulate that individual demands in both countries are symmetric. ${ }^{5}$ Demand functions in both countries can be formulated in the following way, all parameters being positive:

$$
D_{1}(q)=\frac{m \cdot n(a-q)}{b}
$$

4 It is worth mentioning that none of these models directly deals with INIs.

5 It may seem more natural to use a proportion of the number of inhabitants for aggregation. In our opinion, GDP recalculated according to purchasing power parity gives a better picture of the market size. Such a definition of a weight can partially remove the restriction following from the assumption of symmetrical demand functions in both countries. 
for Country 1 and similarly

$$
D_{2}(q)=\frac{m(a-q)}{b}
$$

for Country 2.

Our thought, following Haufler \& Wooton (1999), is based on comparison of gains of the company in dependence on its choice of the country. May the company decide for an investment into Country 1 . Then it will produce in Country 1 and export part of this production to Country 2 . In Country 1, the company sells its products for the optimal price $p_{1}$. However, in consequence of the existence of transaction costs, in the second country's market the demand price is raised by $t$, while the MNC still obtains $p_{1}$.

Let $q_{\mathrm{i}}$ be the final demand price of goods in country $i$. Let us assume a linear production function with the only variable factor - labour. For Country 1 suppose that the wage costs are $k$-times higher than in Country 2:

$$
w_{1}=k w_{2} \text {. }
$$

Assumption 4. Similarity Investment risk is the same for both countries and there is no further relevant difference between the countries than is expressed by the CIT rate $\left(\tau_{i}\right)$ and parameters $n$ and $k$.

\subsection{Optimization}

Because the only production factor is wage costs, we can directly write down an MNC's profit function for the first country:

$$
\pi_{1}=\left(p_{1}-w_{1}\right)\left[D_{1}\left(q_{1}\right)+D_{2}\left(q_{2}\right)\right] .
$$

Substituting (1), (2) and (3) into (4) and rearranging, we obtain

$$
\pi_{1}=\frac{m\left(p_{1}-k w_{2}\right)}{b}\left[\left(a-p_{1}\right)(n+1)-t\right] .
$$

The condition of the first order is

$$
\frac{\partial \pi_{1}}{\partial p_{1}}=\frac{m(n+1)}{b}\left(a-2 p_{1}+k w_{2}-\frac{t}{n+1}\right)=0 .
$$

Formulating price $p_{1}$ from (5), we get

$$
p_{1}=\frac{1}{2}\left(a+k w_{2}-\frac{t}{n+1}\right) .
$$

The maximum can be verified by the condition of the second order: 


$$
\frac{\partial^{2} \pi_{1}}{\partial p_{1}^{2}}\left[\frac{1}{2}\left(a+k w_{2}-\frac{t}{n+1}\right)\right]=-2 \frac{m(n+1)}{b} .
$$

Substituting the optimal price into the profit function yields

$$
\pi_{1}=\frac{m\left[(n+1)\left(a-k w_{2}\right)-t\right]^{2}}{4 b(n+1)} .
$$

In the same manner it is necessary to derive the formula for the second country. Let us proceed analogically to get

$$
\pi_{2}=\frac{m\left[(n+1)\left(a-w_{2}\right)-n t\right]^{2}}{4 b(n+1)} .
$$

Until this moment we followed the approach of Haufler, Wooton (1999) and Sedmihradský (2002), only several smaller modifications have been made. The continuation varies.

Let us define the net present value of investment in Country 1 as

$$
N P V_{1}=\sum_{i=1}^{Y_{1}} \frac{\pi_{1}}{(1+r)^{i}}+\sum_{j=Y_{1}+1}^{M} \frac{\pi_{1}\left(1-\tau_{1}\right)}{(1+r)^{j}}-F,
$$

where $Y_{1}$ denotes the duration of investor's total tax relief granted by Country 1 .

Assumption 5. There is no other form of INIs except the total CIT relief. ${ }^{6}$

Let $M$ denote investment lifetime, $F$ investment volume, $\tau_{1}$ statutory CIT rate, and $r$ discount rate. No inflation is considered. All parameters are positive and $\tau_{1} \in(0,1)$.

We shall formulate the model in discrete time. In period 0 , the company does not generate any profit, but expends fixed costs $F$. Then there is a constant flow of profits in periods 1 to $M$. In periods 1 to $Y_{1}$, the company exercises INIs. From year $Y_{1}+1$ till the end of investment's lifetime, the profit of the company is taxed by the usual CIT rate of Country 1 . Discount rate is constant throughout the investment lifetime and is the same for both countries. Substituting (6) into (8) yields

$$
\begin{aligned}
N P V_{1} & =\sum_{i=1}^{Y_{1}} \frac{m\left[(n+1)\left(a-k w_{2}\right)-t\right]^{2}}{4 b(n+1)(1+r)^{i}} \\
& +\sum_{j=Y_{1}+1}^{M} \frac{m\left[(n+1)\left(a-k w_{2}\right)-t\right]^{2}\left(1-\tau_{1}\right)}{4 b(n+1)(1+r)^{j}}-F .
\end{aligned}
$$

The similar stands for Country 2:

6 With regard to this assumption let us use the terms "total tax relief", "tax allowances", "tax holidays" and "INIs" as synonyms on the following pages. 


$$
\begin{aligned}
N P V_{2} & =\sum_{i=1}^{Y_{2}} \frac{m\left[(n+1)\left(a-w_{2}\right)-n t\right]^{2}}{4 b(n+1)(1+r)^{i}} \\
& +\sum_{j=Y_{2}+1}^{M} \frac{m\left[(n+1)\left(a-w_{2}\right)-n t\right]^{2}\left(1-\tau_{2}\right)}{4 b(n+1)(1+r)^{j}}-F .
\end{aligned}
$$

If profit parity is valid for both countries, that means if investor is indifferent when deciding to which country to place his investment, the following must stand:

$$
\begin{aligned}
& \sum_{i=1}^{Y_{1}} \frac{\left[(n+1)\left(a-k w_{2}\right)-t\right]^{2}}{(1+r)^{i}}+\sum_{j=Y_{1}+1}^{M} \frac{\left[(n+1)\left(a-k w_{2}\right)-t\right]^{2}\left(1-\tau_{1}\right)}{(1+r)^{j}}= \\
& =\sum_{i=1}^{Y_{2}} \frac{\left[(n+1)\left(a-w_{2}\right)-n t\right]^{2}}{(1+r)^{i}}+\sum_{j=Y_{2}+1}^{M} \frac{\left[(n+1)\left(a-w_{2}\right)-n t\right]^{2}\left(1-\tau_{2}\right)}{(1+r)^{j}} .
\end{aligned}
$$

Consequently, neither the number of inhabitants of Country 2 nor fixed investment costs will have any influence on the result. We facilitate the situation by installing zero discount rate for further steps. ${ }^{7}$ Thus we can write

$$
\begin{aligned}
& Y_{1}\left[(n+1)\left(a-k w_{2}\right)-t\right]^{2}+\left(M-Y_{1}\right)\left(1-\tau_{1}\right)\left[(n+1)\left(a-k w_{2}\right)-t\right]^{2}= \\
& =Y_{2}\left[(n+1)\left(a-w_{2}\right)-n t\right]^{2}+\left(M-Y_{2}\right)\left(1-\tau_{2}\right)\left[(n+1)\left(a-w_{2}\right)-n t\right]^{2} .
\end{aligned}
$$

After rearrangements and extraction of $Y_{1}$, we get

$$
Y_{1}=\left[\frac{(n+1)\left(a-w_{2}\right)-n t}{(n+1)\left(a-k w_{2}\right)-t}\right]^{2} \frac{M\left(1-\tau_{2}\right)+Y_{2} \tau_{2}}{\tau_{1}}-\frac{M\left(1-\tau_{1}\right)}{\tau_{1}} .
$$

Due to (6) and (7), (9) can be also written as

$$
Y_{1}=\frac{\frac{\pi_{2}}{\pi_{1}}\left[M\left(1-\tau_{2}\right)+Y_{2} \tau_{2}\right]-M\left(1-\tau_{1}\right)}{\tau_{1}} .
$$

\subsection{Comparative Statics}

Definition 2. Let us set the relative quality of entrepreneurial environment in country $i$ as the ratio $\pi_{i} / \pi_{j}$. If this is more than 1 , the environment in country $i$ is better than in country $j$.

7 Counting with nonzero discount rate does not bring any additional value added regarding the key results of the model; and it can be shown that there exists no closed-form solution in such a case. Moreover, since there is a constant flow of profits, we find this simplification even consistent. One could equivalently suppose that the flow of profits is rising each year by such a coefficient that would compensate the fact of future profits being discounted. Ad libitum. 
Proposition 1. Minimal sustainable tax benefit of country $i$ is ceteris paribus descending in the quality level of the entrepreneurial environment in $i$.

Proof. First, let us differentiate (10):

$$
\frac{\partial Y_{1}}{\partial\left(\frac{\pi_{1}}{\pi_{2}}\right)}=\frac{-\left(\frac{\pi_{1}}{\pi_{2}}\right)^{-2}\left[M\left(1-\tau_{2}\right)+Y_{2} \tau_{2}\right]}{\tau_{1}}
$$

For $\tau_{2} \in(0,1)$ the expression $M\left(1-\tau_{2}\right)+Y_{2} \tau_{2}$ is always nonnegative, as the duration of tax holidays cannot exceed investment lifetime. Thus, the numerator is negative as well as the whole derivative.

Proposition 2. Minimal sustainable incentive level in country $i$ is increasing in the relative price of its labour power.

Proof. Realizing that $k$ negatively influences the profit of the company in Country 1 , but does not affect its profit in Country $2, \pi_{2} / \pi_{1}$ increases and the attractiveness of Country 1's entrepreneurial environment decreases. Following Proposition 1, the critical subsidy level in Country 1 must increase.

Proposition 3. Strong competition Minimal sustainable INI in country $i$ is increasing in CIT of country $i$, if relative entrepreneurial environment in country $i$ is better than in country $j$.

Proof. Examining an influence of the CIT rate on the critical benefit period, let us differentiate:

$$
\frac{\partial Y_{1}}{\partial \tau_{1}}=\frac{M-\frac{\pi_{2}}{\pi_{1}}\left[M\left(1-\tau_{2}\right)+Y_{2} \tau_{2}\right]}{\tau_{1}^{2}} .
$$

Because $M\left(1-\tau_{2}\right)+Y_{2} \tau_{2}$ is always less or equal to $M$ and since the ratio $\pi_{2} / \pi_{1}$ is less than 1 , numerator in (11) will be positive. Let us note that if the last condition does not stand, nothing about the sign of the derivation can be said. Thus it is possible that $Y_{1}$ need not be increasing in $\tau_{1}$; for instance, if Country 2 is much larger, richer or notably cheaper in terms of labour costs, and $\tau_{2}$ is simultaneously close to zero (or, analogically, $Y_{2} \rightarrow M$ ). But such a counter-intuitive result requires drastic assumptions; therefore we do not consider it to be a representative feature of this model.

Proposition 4. Weak competition Minimal sustainable incentive level in country $i$ is increasing in the subsidy range of country $j$.

Proof. Dependence of the critical incentive level in country $i$ on the stimuli duration of country $j$ is very simple:

$$
\frac{\partial Y_{1}}{\partial Y_{2}}=\frac{\pi_{2} \tau_{2}}{\pi_{1} \tau_{1}}
$$

The result is evident due to Assumption 3 and positive $\tau_{i}$. 
Instead of differentiating (10) with respect to all variables, it is more convenient to demonstrate model functioning on a simple example. Let us choose initial parameters (line 1 in Table 1) and calibrate the model, followed by the discussion of relatively more relevant parameters.

Example 1. Presumed investment lifetime is 20 years. Let $a$, the parameter of investors' demand, be 100 . Workload needed to produce a unit of commodity is $\$ 10$ for Country 2, $\$ 12$ for Country 1 . Country 1 has twice as large market as its rival. Transportation of goods to the other country means additional costs of \$10. CIT rate is $30 \%$ in both countries; Country 2 provides tax holidays to each foreign investment for 10 years, automatically. The competitor decides ad hoc, individually for each investor. The question is, how rich incentives Country 1 has to grant to make investors indifferent between the two countries.

Table 1

Sensibility of the Minimal Sufficient INI Model

\begin{tabular}{|l|r|r|r|r|r|r|r|r|r|}
\hline Line No. & $\boldsymbol{Y}_{\mathbf{1}}$ & $\boldsymbol{Y}_{\mathbf{2}}$ & $\tau_{\mathbf{1}}$ & $\boldsymbol{\tau}_{2}$ & $\boldsymbol{a}$ & $\boldsymbol{n}$ & $\boldsymbol{k}$ & $\boldsymbol{M}$ & $\boldsymbol{t}$ \\
\hline 1 & 8.23 & 10 & 0.3 & 0.3 & 100 & 2 & 1.2 & 20 & 10 \\
\hline 2 & 13.07 & 15 & 0.3 & 0.3 & 100 & 2 & 1.2 & 20 & 10 \\
\hline 3 & 3.39 & 5 & 0.3 & 0.3 & 100 & 2 & 1.2 & 20 & 10 \\
\hline 4 & 11.17 & 10 & 0.4 & 0.3 & 100 & 2 & 1.2 & 20 & 10 \\
\hline 5 & 2.34 & 10 & 0.2 & 0.3 & 100 & 2 & 1.2 & 20 & 10 \\
\hline 6 & 5.00 & 10 & 0.3 & 0.4 & 100 & 2 & 1.2 & 20 & 10 \\
\hline 7 & 11.46 & 10 & 0.3 & 0.2 & 100 & 2 & 1.2 & 20 & 10 \\
\hline 8 & 9.85 & 10 & 0.3 & 0.3 & 1 & 2 & 1.2 & 20 & 10 \\
\hline 9 & 5.72 & 10 & 0.3 & 0.3 & 50 & 2 & 1.2 & 20 & 10 \\
\hline 10 & 4.04 & 10 & 0.3 & 0.3 & 100 & 5 & 1.2 & 20 & 10 \\
\hline 11 & 12.76 & 10 & 0.3 & 0.3 & 100 & 1 & 1.2 & 20 & 10 \\
\hline 12 & 12.34 & 10 & 0.3 & 0.3 & 100 & 2 & 1.5 & 20 & 10 \\
\hline 13 & 3.39 & 10 & 0.3 & 0.3 & 100 & 2 & 0.8 & 20 & 10 \\
\hline 14 & 7.86 & 10 & 0.3 & 0.3 & 100 & 2 & 1.2 & 25 & 10 \\
\hline 15 & 8.96 & 10 & 0.3 & 0.3 & 100 & 2 & 1.2 & 10 & 10 \\
\hline 16 & 3.68 & 10 & 0.3 & 0.3 & 100 & 2 & 1.2 & 20 & 20 \\
\hline 17 & 10.44 & 10 & 0.3 & 0.3 & 100 & 2 & 1.2 & 20 & 5 \\
\hline
\end{tabular}

Source: author's computations on the basis of result (10).

First column of the first line of Table 1 shows the situation from Example 1, where tax exemption of 8.2 years suffices. What happens if Country 2 changes its strategy? Apparently, increases in the duration of tax holidays in Country 2 force the first country to raise its incentive almost proportionally. This results already from Proposition 4.

In accordance with Proposition 3, raising CIT in Country 1 by one third increases the minimal sufficient INI by 3 years, and vice versa. Changes in CIT of the rival 
country will have an antagonistic effect. Rising CIT of Country 2 to $40 \%$ results in a decrease of the critical period of tax relief to 5 years; on the other hand, a shift to $20 \%$ will lead to an increase of subsidy to 11.5 years.

It is obvious that multiple changes in parameter $a$ may influence incentives only a little. The next two lines show an impact of changes in relative economic power the stronger purchasing power Country 1 has, the smaller amount of INIs the country has to provide. In lines 12 and 13 changes in relative wage costs are itemized. The growth in costs of Country 1 (represented by the rise of $k$ from 1.2 to 1.5 ) means an escalation in minimal sufficient incentive to 12.3 years - wage costs have a noticeable impact on the critical length of subsidy, in line with Proposition 2. Conversely, a change in investment lifetime $M$ will not influence critical length of subsidy very much for such selected parameters' values.

Proposition 5. Investment lifetime's neutrality If both countries have the same CIT and quality of entrepreneurial environment, the investment lifetime does not affect the critical rate of INI.

Proof. Differentiating (10) with respect to $M$ yields:

$$
\frac{\partial Y_{1}}{\partial M}=\frac{\frac{\pi_{2}}{\pi_{1}}\left(1-\tau_{2}\right)-\left(1-\tau_{1}\right)}{\tau_{1}} .
$$

Employing both assumptions, the result is evident.

Simultaneously, if Country 1 has better entrepreneurial environment than Country 2 but higher CIT, the critical rate of incentive will grow in M. In this case, competing with a more populous, poorer country with lower CIT rate (say, the Czech Republic vs. Poland), a relatively smaller and richer country with higher CIT has to offer noticeably higher incentives for long-term investments. This fact is overestimated because of the condition of zero discount rate (in comparative statics, influence of $\mathrm{M}$ is the only aspect strongly affected by this condition). Finally, if transaction costs are relatively high (line 16), the market of the larger country (Country 1) is worse accessible and the company will rather decide to invest directly there. Minimal sustainable incentive for this country decreases relatively fast.

\subsection{Application on the Visegrad Countries}

Definition 3. The term incentive parity signifies a situation, when potential NPV of the investment is the same for both countries.

In Table 2, all essential parameters are summarized for all four countries of Visegrad group as of 2005. They were chosen on purpose; these countries are competitors to large extent and there are no drastic divergences in economic performance and institutional system, so that they largely satisfy the assumption of similarity (Assumption 4). 
Table 2.

Chosen Indicators for Surveyed Countries

\begin{tabular}{|l|r|r|r|r|}
\hline 2005 & Czech Rep. & \multicolumn{1}{c|}{ Slovakia } & Poland & Hungary \\
\hline GDP & 187,611 & 86,753 & 495,885 & 169,875 \\
\hline W & 1,096 & 704 & 887 & 921 \\
\hline CIT & $24 \%$ & $19 \%$ & $19 \%$ & $16 \%$ \\
\hline Y & 10 & 10 & F/2 & 8 \\
\hline
\end{tabular}

Notes:

GDP-Value is in millions of USD according to PPP.

W-Total wage costs- "supergross wage" in USD per month, recounted by average exchange rate of 2005.

Poland does not have any time limit of tax relief utilization, but (in most of the country) it allows to use allowances up

to one half of initial investment-it takes an advantage of effective European legislation. Since it is a higher allowance than in the Czech Republic, let us approximate it to, for instance, 12 years (a rather conservative estimation)

Hungary provides $80 \%$ CIT reliefs for up to 10 years, which is approximated to 8 years of total tax relief.

Source: IMF (2006, estimates), Gola (2006), Devereux (2006), www.czechinvest.cz, www.sario.sk, www.paiz.gov.pl, www.itd.hu.

On the basis of line 1 from Table 2, let us calculate $n$, i.e., population purchasing power ratio, while from the second row we ascertain $k$ for all countries regarding the Czech Republic (CR). The question is how rich incentive the CR has to offer to keep the investor indifferent.

Table 3.

Results of Critical Tax-relief Period Rate for the Czech Republic

\begin{tabular}{|l|c|c|c|c|c|c|c|c|c|c|}
\hline Case & $\boldsymbol{Y}_{\mathbf{1}}$ & $\boldsymbol{Y}_{\mathbf{1}}$ & $\tau_{1}$ & $\tau_{2}$ & $\boldsymbol{a}$ & $\boldsymbol{n}$ & $\boldsymbol{k}$ & $\boldsymbol{W}_{\mathbf{2}}$ & $\boldsymbol{M}$ & $\boldsymbol{t}$ \\
\hline CR - Slovakia & 10.9 & 10 & 0.24 & 0.19 & 1,000 & 2.16 & 1.56 & 5 & 15 & 10 \\
\hline CR - Poland & 13.3 & 12 & 0.24 & 0.19 & 1,000 & 0.38 & 1.24 & 5 & 15 & 10 \\
\hline CR - Hungary & 10.4 & 8 & 0.24 & 0.16 & 1,000 & 1.10 & 1.19 & 5 & 15 & 10 \\
\hline CR - Slovakia & 8.5 & 10 & 0.15 & 0.19 & 1,000 & 2.16 & 1.56 & 5 & 15 & 10 \\
\hline CR - Poland & 12.3 & 12 & 0.15 & 0.19 & 1,000 & 0.38 & 1.24 & 5 & 15 & 10 \\
\hline CR - Hungary & 7.6 & 8 & 0.15 & 0.16 & 1,000 & 1.10 & 1.19 & 5 & 15 & 10 \\
\hline
\end{tabular}

Source: author's computations from Table 2 and result (10).

In the first part of Table 3, let us examine the case of $24 \%$ CIT rate in the Czech Republic, as of 2007. In the second part, we try to analyse how the result would change if the Czech CIT rate decreased to, say, $15 \%$. As we see, in the first case (present situation), INIs were set broadly at par to Slovakia and Hungary - the model results give 10.9 and 10.4 respectively, not far from the real value (10 years). However, Poland had the parity much higher - at 13.3 years. The market size has the greatest impact on this outcome; recalling that the model does not assume purely vertical FDI, this result is not really surprising.

If tax rate had been reduced all the way to $15 \%$ in the Czech Republic, incentive parity would have decreased noticeably toward Hungary as well as toward Slovakia. The CR could allow decreasing amount of INIs, admittedly at the risk of losing some 
marginal investors in favour of Poland (with Poland, parity stays steadily above 10 years). If the incentive provision is fully stopped after tax reduction to $15 \%$, parity would not hold even vis-à-vis Hungary and Slovakia, and it would not be convenient for the investor in this model to invest in the CR. For instance vis-à-vis Slovakia, the Czech Republic would have to reduce CIT down to $6.5 \%$ to compensate the investor for the abolition of present INIs.

\subsection{Limitations \& Extensions}

It stands to reason that model results from Table 3 should be taken "with a grain of salt". We do not claim that incentive parity actually holds (or hold) in Central Europe; it was merely an illustrative example. The model is very simple in methodology, also engaging only in a restricted number of parameters - certainly there is different labour productivity among the examined countries, regardless of many other FDI determinants. Each country has certain specific assets (e.g., location) important for investors, but hardly quantifiable. The other possible improvement is to use effective instead of statutory corporate income tax rate.

Naturally, income tax relief is not the only form of INIs that governments keep at disposition, although it is probably the most utilized one (Newton, 2003). For advanced countries, which usually prioritize financial subsidies, ${ }^{8}$ such precondition is particularly restrictive while in other countries, tax holidays make usually a noticeable part of the whole INI. For instance according to the Czech Supreme Audit Office report (SAO 2006, pp. 9), the CR provided CIT reliefs in the amount of 5,102 million CZK in 1998-2005, compared to financial INIs of 247 million CZK. CIT reliefs thus represented more than $95 \%$ of the total provided volume of INIs. However, it might be useful to expand the model by other kinds of incentives, especially the financial ones.

\section{The Optimal INI Model}

\subsection{Intuition and Methodology}

While the model introduced in the last section formulated the minimal INI adequate to keep investor indifferent in decision-making between both countries, now we try to determine how large INI is really optimal for the given country. With reference, inter alia, to Blomström, Kokko (2003), we consider FDI as a public good associated with externalities (naturally under certain circumstances, which is not a subject of discussion here). For this chapter let us consider only positive FDI externalities positive productivity spillovers.

The model from the last chapter is solved from investor's point of view - the government has only a possibility to change the volume of INIs in reaction to investor's profit parity. In this model, we will approach the situation directly from the chosen country's view. Nevertheless, the attitude toward the problem will be opposite

8 One of the exceptions is for instance Singapore (Sieh Lee 1998). 
to what is common in available literature. Very often we can encounter such a formulation that - by means of incentives - governments buy spillovers (e.g., Newton, 2003; Ma, 2007). Sometimes, the competition for FDI is directly compared to an auction: the MNC auctions FDI, governments try to outbid each other (see Besley, Seabright, 1999).

In such a case, one would assume INIs to be a form of a price which countries pay for FDI or directly for spillovers connected to it. Our approach in this chapter is, however, not so straightforward. The introduced model is based on understanding INIs as commodities of some kind produced by the government and demanded by potential investors. Nevertheless, INIs of both countries are not identical for the MNC - let us simply assume that the MNC perceives incentives of Country 1 and Country 2 as different, although related, goods. To formalize, we see a certain analogy with the Cournot oligopoly model, because the way of maximization (modifications of the offered quantity) corresponds to our thinking about incentives-based competition for FDI the best.

Why did we decide to interpret the issue precisely in this manner, quite differently from formulations of existing models? If an MNC plans to invest, it usually makes a list of several acceptable countries or regions. Their governments are then contacted in an effort to obtain the best INI possible (see, e.g., Oman, 2000). At this stage, FDI competition is reduced to the incentives-based rivalry concerning usually only a few countries - therefore we consider oligopoly in our model. Understanding INIs as a commodity enables us to illustrate the nature of the prisoner's dilemma, which burdens this competition. Since we want to apply the Cournot oligopoly model, MNC's inverse demand functions (quasiprice which the MNC "pays" for INIs) need to be derived. However, we simply assume here that the inverse demand functions have the shape described in the following paragraphs.

Let us divide host country's benefits from FDI into $(i)$ productivity spillovers and (ii) other effects (nonexternalities). The MNC is aware of positive externalities generated by its investments (denoted by $\xi$ ), but it cannot influence the size of such spillovers (denoted by $\xi$ ). Thus this value will form the autonomous term in inverse demand function (12). May the MNC's willingness to pay for INIs refer to the other FDI effects in our model. These are determined by the MNC itself and can be either positive or negative. The higher CIT rate in a certain country, the more willing the $\mathrm{MNC}$ is to pay for INIs offered by this country (parameter $\alpha_{i}$ in (12) will be positive). Higher tax burden in the country providing INIs means that the incentive presents a higher utility for the investor - and he is now willing to "pay" a higher quasi price.

Analogically, the higher the CIT rate in the rival country, the less ready the MNC is to pay for incentives of the first country (product of $\beta_{i}$ and $\tau_{j}$ will be negative). As with the CIT increase in Country 2 the MNC does not demand high incentives in Country 1 (Country 2 is getting ceteris paribus less competitive and the negotiating power of Country 1 strengthens), its willingness to pay for INIs of Country 1 decreases. Finally, the quasi price will fall with an increase of provided volume of INIs by the given country - the same as with an increase of INIs of the rival country 
since the MNC perceives them as relatively close substitutes. In other words, we assume downward-sloping demand curves.

\subsection{Basic Assumptions}

Assumption 6. Separation Let us consider the decision making to be separate for INIs and the CIT rate. The latter is set exogenously and government seeks the optimal INI.

Assumption 7. Exclusivity The government has merely one form of INIs at its disposal, the total CIT relief for $Y$ years. Furthermore, tax holidays are granted automatically so that each foreign investor can be sure to obtain them.

Assumption 8. For the sake of simplicity, let us consider a model of duopoly competitors. Both countries have certain specific assets for investors (e.g., a favourable location), so that after a simultaneous reduction of incentives from the Cournot equilibrium, investor does not decide to exit into a third country. Let the inverse demand functions be linear in $\tau_{i}$ and $Y_{\mathrm{i}}$.

May the inverse demand functions for INIs be (see discussion in Subsection 3.1)

$$
\varphi_{i}\left(Y_{i}, Y_{j}\right)=\xi_{i}+\alpha_{i} \tau_{i}-\beta_{i} \tau_{j}-\gamma_{i} Y_{i}-\delta_{i} Y_{j}, \quad i, j \in\{1,2\}, \quad i \neq j,
$$

where $\xi_{i}$ stands for spillovers, $\tau_{i} \in(0,1)$ is statutory CIT rate in country $i$ and $Y_{\mathrm{i}}$ is the length of the total CIT relief in years. All the parameters are positive and moreover assume that $\alpha_{i}>\beta_{i}>\gamma_{i}>\delta_{i}$ holds. The reason is the following: taking into account that investor's preferences about the CIT rate and duration of tax holidays probably do not differ significantly and since $\alpha_{i}$ and $\beta_{i}$ influence the tax rate for which the restriction $\tau \in(0,1)$ holds, they should be higher than $\gamma_{i}$ and $\delta_{i}$. It is also reasonable to assume that in each inverse demand function for country $i$ 's INIs, $\tau_{i}$ has higher impact than $\tau_{j}$ as well as the importance of $Y_{\mathrm{i}}$ exceeds that of $Y_{\mathrm{j}}$, therefore $\alpha_{i}>\beta_{i}$ and $\gamma_{i}>\delta_{i}$ holds.

To form a model, we need to choose a way of countries' costs-of-incentives expression. The methodology differs; usually one can encounter an erosion of tax system and home firms' discrimination, since they are often unable to obtain INIs (Oman, 2000). However, these factors can be quantified only with difficulties. In the present paper, we use Wells et al. (2001): the costs of tax holidays can be understood as the relief duration in years multiplied by the CIT rate, overall FDI coming to the country $(I)$, expected gross investment rate of return $(J)$ and the so-called redundancy rate $(R)$ :

$$
T C_{i}=\tau_{i} R_{i} I_{i} J_{i} Y_{i}
$$

where $R_{i} \in(0,1]$ is that part of investors that would have come to the country even without any INIs. Expression (13) then forms the lost tax income.

Assumption 9. Weak INIs' efficiency The received incentive is for all investors the smallest necessary to make them invest into the country. 
$I_{\mathrm{i}}$ and $R_{\mathrm{i}}$ are dependent on $Y_{\mathrm{i}}$, so they are not parameters. $R$ is in fact a function of $Y$, comprehended in form of

$$
R(Y)=1-w(Y),
$$

where $w(Y)$ stands for the function for which the following properties apply:

$$
w \in C^{1}(R), w\left(0 \quad \neq 0, \lim _{Y \rightarrow \infty} w(Y)=1, w^{\prime}(Y) \geq 0, w^{\prime \prime}(Y) \leq 0 .\right.
$$

Lemma 1. If $T C_{i}=\tau_{i} R_{i} I_{i} J_{i} Y_{i}$ holds, then $T C_{i}=\tau_{i} I_{i}^{0} J_{i} Y_{i}$ holds as well, where $I_{i}^{0}$ is the investment volume in the case of nonexistence of INIs.

Explanation. If a country does not provide INIs, then $R=1$; i.e., all investors naturally come into the country without any INIs and $I=I^{0}$. As soon as the country starts to increase INIs, from the definition of $R$, incoming investment volume will rise according to the equation $I=I^{0}+(1-R) I$. Sensibility of investors to INIs is represented by $(1-R)$, which is precisely $w(Y)$. Then, the investment can be derived easily as $I=I^{0} / R$ and after insertion into (13), we obtain the desired expression.

Assumption 10. Symmetry Spillover value and the average rate of return on investment is the same for both countries. In the case of nonexistence of INIs, let the investment inflow be identical for both countries.

Assumption 11. Countries provide generic incentive schemes - we do not consider for now that governments have a possibility to negotiate with individual investors. Countries offer INIs ex ante, being the same for all investors.

\subsection{Decentralized Equilibrium}

Let both countries be Cournot duopolists maximizing their individual profit. None of the countries has perfect information about the exact volume of INIs offered by the second country at its disposal. The total revenue from INIs of Country 1 will then be

$$
T R_{1}\left(Y_{1}, Y_{2}\right)=\xi Y_{1}+\alpha_{1} \tau_{1} Y_{1}-\beta_{1} \tau_{2} Y_{1}-\gamma_{1} Y_{1}^{2}-\delta_{1} Y_{1} Y_{2} .
$$

Applying Lemma 1, the total costs of INIs will reach

$$
T C_{1}=\tau_{1} I^{0} J Y_{1}
$$

On the basis of (14) and (15), one can formulate the profit function (where as the "profit" we consider the utility of the given country from provided INIs):

$$
\Pi_{1}=\xi Y_{1}+\alpha_{1} \tau_{1} Y_{1}-\beta_{1} \tau_{2} Y_{1}-\gamma_{1} Y_{1}^{2}-\delta_{1} Y_{1} Y_{2}-Y_{1} \tau_{1} I^{0} J .
$$

From the condition of the first order, we solve for $Y_{1}$ and obtain the reaction function of Country 1:

$$
Y_{1}=\frac{\xi+\alpha_{1} \tau_{1}-\beta_{1} \tau_{2}-\delta_{1} Y_{2}-\tau_{1} I^{0} J}{2 \gamma_{1}}
$$


Similarly, let us derive the reaction function of Country 2 :

$$
Y_{2}=\frac{\xi+\alpha_{2} \tau_{2}-\beta_{2} \tau_{1}-\delta_{2} Y_{1}-\tau_{2} I^{0} J}{2 \gamma_{2}} .
$$

Terms (16) and (17) give together a system of equations - two reaction curves. The final Cournot equilibrium will be reached in the point of intersection of these curves. After modifications and substitution, the equilibrium value will have the form of

$$
\begin{aligned}
Y_{1}^{C} & =\frac{\xi\left(2 \gamma_{2}-\delta_{1}\right)+\tau_{1}\left(2 \alpha_{1} \gamma_{2}+\delta_{1} \beta_{2}-2 \gamma_{2} I^{0} J\right)}{4 \gamma_{1} \gamma_{2}-\delta_{1} \delta_{2}} \\
& -\frac{\tau_{2}\left(2 \beta_{1} \gamma_{2}+\alpha_{2} \delta_{1}-\delta_{1} I^{0} J\right)}{4 \gamma_{1} \gamma_{2}-\delta_{1} \delta_{2}} .
\end{aligned}
$$

(18) sets the optimal volume of INIs for Country 1, provided no country has "an advantage of the first move" and no agreement is possible - we deal with a simultaneous noncooperative one-shot game.

Both propositions in this subsection are straightforward applications of equilibrium condition (18). Let us start with the influence of spillovers.

Proposition 6. The amount of incentives under "free subsidy competition" in the Cournot equilibrium is an increasing function of positive FDI spillovers.

Proof. Let us simply differentiate (18):

$$
\frac{\partial Y_{1}}{\partial \xi}=\frac{2 \gamma_{2}-\delta_{1}}{4 \gamma_{1} \gamma_{2}-\delta_{1} \delta_{2}} .
$$

Being aware of the primary condition $\gamma_{i}>\delta_{i}$, we get the result.

Proposition 7. The host country's CIT rate $\left(\tau_{1}\right)$ has an ambiguous effect on the optimal level of INIs. The effect tends to be negative if many MNCs are willing to invest into the country even without any incentives and if the returns on such investments are high.

Proof. It is necessary to differentiate (18) with respect to $\tau_{1}$ :

$$
\frac{\partial Y_{1}}{\partial \tau_{1}}=\frac{2 \alpha_{1} \gamma_{2}+\delta_{1} \beta_{2}-2 \gamma_{2} I^{0} J}{4 \gamma_{1} \gamma_{2}-\delta_{1} \delta_{2}} .
$$

The denominator is positive, but we cannot say anything about the sign of the nominator. This can be surprising because the CIT rate is naturally closely related to tax incentives in MNCs' decision-making and one would expect the influence to be clearly positive. However, in the current model, the amount of lost taxation rises with the increasing CIT and, on the other hand, the higher CIT, the more INIs investors require since their net rate of return declines - see definition of the respective demands in (12) -, which increases government's revenue from the provision of INIs. The total effect is slight and unclear. Differentiation with respect to $\tau_{2}$ yields a very 
similar formula with opposite signs - thus it seems that if $\tau_{1}$ increases $\mathrm{Y}_{1}, \tau_{2}$ tends to decrease it, and vice versa.

Parameter $\gamma_{1}$ raises the denominator in (18), but does not affect the numerator, thus the optimal volume of INIs decreases with its growth. Parameter $\delta_{2}$ has a contrary influence; it decreases the denominator, but does not occur in the numerator. It is not so simple to estimate the impact of other parameters; therefore we project the performance of the model on an example and in particular on Table 4.

Example 2. For illustration, let the Czech and Slovak Republics be competitors and the respective demand functions for INIs be symmetrical. Let us select the following demand parameters: $\alpha_{i}=100, \beta_{i}=50, \gamma_{i}=20, \delta_{i}=10$. Spillovers are assessed to be 400 . Assume that the investment value which would come to the country even without incentives is equal to 1000 and its average rate of return is $10 \%$. In 2007, the CIT rate was $19 \%$ in Slovakia and $24 \%$ in the Czech Republic. This example is described in the first line of Table 4 - the optimal tax relief provided by the CR will last for 7.8 years under these conditions. What happens if the spillover effect rises by $50 \%$ to 600 ? The optimal INI increases to 11.8 years.

\subsection{Stackelberg Leadership}

Admittedly, simultaneous game principle does not have to be fulfilled in practice. Suppose that the government of Country 1 has "an advantage of the first move", so that Country 1 is a quantity leader in the sense of Stackelberg. The country that is the first one to provide INIs in the region or which is the most successful in attracting foreign investors can become such a leader. In the last decades, Singapore can serve as an example for the region of Southeastern Asia (see Charlton, 2003). Country 1 (leader) knows ex ante that Country 2 (follower) will react to its move. Government in Country 1 knows the reaction function of Country 2:

$$
Y_{2}=\frac{\xi+\alpha_{2} \tau_{2}-\beta_{2} \tau_{1}-\delta_{2} Y_{1}-\tau_{2} I^{0} J}{2 \gamma_{2}},
$$

Thus Country 1 uses the reaction function of Country 2 in its profit function:

$$
\begin{aligned}
\Pi_{1} & =\xi Y_{1}+\alpha_{1} \tau_{1} Y_{1}-\beta_{1} \tau_{2} Y_{1}-\gamma_{1} Y_{1}^{2} \\
& -\delta_{1} Y_{1} \frac{\xi+\alpha_{2} \tau_{2}-\beta_{2} \tau_{1}-\delta_{2} Y_{1}-\tau_{2} I^{0} J}{2 \gamma_{2}}-Y_{1} \tau_{1} I^{0} J
\end{aligned}
$$

From the condition of the first order we derive $Y_{1}$ and get the optimal amount of incentives in Country 1 for the leader of the sequential game: 


$$
\begin{aligned}
Y_{1}^{S} & =\frac{\xi\left(2 \gamma_{2}-\delta_{1}\right)+\tau_{1}\left(2 \alpha_{1} \gamma_{2}+\delta_{1} \beta_{2}-2 \gamma_{2} I^{0} J\right)}{4 \gamma_{1} \gamma_{2}-2 \delta_{1} \delta_{2}} \\
& -\frac{\tau_{2}\left(2 \beta_{1} \gamma_{2}+\alpha_{2} \delta_{1}-\delta_{1} I^{0} J\right)}{4 \gamma_{1} \gamma_{2}-2 \delta_{1} \delta_{2}} .
\end{aligned}
$$

Proposition 8. Duration of tax relief in the case of the Stackelberg leadership stays greater than in the case of Cournot competition.

Proof. The new term has a higher denominator, while the numerator stays the same, therefore $Y_{1}^{C}<Y_{1}^{S}$ always holds.

Analogically to the standard model of the Stackelberg leader, the results are higher provision of INIs and higher "income" for Country 1. Thanks to the similarity of expressions, discussion of parameters influences of the Stackelberg equilibrium will not be necessary because they will not differ from the case of Cournot. Proposition 6 and also all the conclusions made in the discussion about (18) are valid here as well.

Example 3. Let all parameters be the same as in Example 2. The Czech Republic and Slovakia are again duopolists providing INIs, but the Czech Republic is now the Stackelberg leader - this modification changes optimal duration of tax holidays to 8.4 years.

\subsection{Supranational Coordination}

Even if the absolute majority of theoretical works calls for some form of global regulation of INIs (see, inter alia, UNCTAD, 1996), it has not appeared in a noticeable extent till nowadays; apparently no credible threat for the case of violation of such agreements exists.

A typical example can be found in Charlton (2003, p. 29): in 1991, the states of New York, New Jersey, and Connecticut made an agreement on restrictions of incentives for investors transferring their activities from one state to another. However, New Jersey promptly violated this contract, trying to attract by an incentive of 50 million dollars First Chicago Corporation, which kept at that time 1,500 employees in the neighbouring New York. New York reacted with even a more generous incentive and made the company stay. As a result, the inter-state agreement lasted for only four days.

Our model changes with the assumption of coordination. To maximize the common profit from INIs, the supranational entity maximizes the profit function

$$
\begin{aligned}
\Pi_{1+2}=\xi & Y_{1}+\alpha_{1} \tau_{1} Y_{1}-\beta_{1} \tau_{2} Y_{1}-\gamma_{1} Y_{1}^{2}-\delta_{1} Y_{1} Y_{2}-Y_{1} \tau_{1} I^{0} J \\
& +\xi Y_{2}+\alpha_{2} \tau_{2} Y_{2}-\beta_{2} \tau_{1} Y_{2}-\gamma_{2} Y_{2}^{2}-\delta_{2} Y_{1} Y_{2}-Y_{2} \tau_{2} I^{0} J .
\end{aligned}
$$


From the first order condition with respect to $Y_{1}$ we derive

$$
Y_{1}=\frac{\xi+\alpha_{1} \tau_{1}-\beta_{1} \tau_{2}-\delta_{1} Y_{2}-\tau_{1} I^{0} J-\delta_{2} Y_{2}}{2 \gamma_{1}}
$$

Similarly from the first order condition with respect to $Y_{2}$ we calculate

$$
Y_{2}=\frac{\xi+\alpha_{2} \tau_{2}-\beta_{2} \tau_{1}-\delta_{2} Y_{1}-\tau_{2} I^{0} J-\delta_{1} Y_{1}}{2 \gamma_{2}}
$$

In the case of both countries' agreement, substituting (22) into (21) we obtain for $Y_{1}$ :

$$
\begin{aligned}
Y_{1}^{K}= & \frac{\xi\left(2 \gamma_{2}-\delta_{1}-\delta_{2}\right)+\tau_{1}\left[2 \gamma_{2}\left(\alpha_{1}-I^{0} J\right)+\beta_{2}\left(\delta_{1}+\delta_{2}\right)\right]}{4 \gamma_{1} \gamma_{2}-\left(\delta_{1}+\delta_{2}\right)^{2}} \\
& -\frac{\tau_{2}\left[2 \beta_{1} \gamma_{2}+\left(\delta_{1}+\delta_{2}\right)\left(\alpha_{2}-I^{0} J\right)\right]}{4 \gamma_{1} \gamma_{2}-\left(\delta_{1}+\delta_{2}\right)^{2}} .
\end{aligned}
$$

Example 4. Following Example 2, the chosen parameters and countries stay the same. Providing both countries are able to agree on incentives-system coordination, the optimal duration of incentive in the Czech Republic will decrease to 6.6 years. However, this conclusion cannot be generalized.

Proposition 9. If both countries are able to coordinate their INI schemes, the offered INIs can either decrease or increase, depending mainly on the assumed spillover value.

Proof. This can be seen easily, e.g., from Table 4 which tests the sensibility of model's results to individual parameters. Through most of the modifications of our example, the optimal tax-relief duration in the case of coordination stays lower than in the decentralized equilibrium. But note the third line-in the case of coordination, INI is higher for such selected parameters' values.

Notice that Proposition 6 and Proposition 7 are valid even in the case of coordination (for the same reasons as in the Cournot model). Also $\gamma_{1}$ affects the optimal incentive value negatively; nonetheless we cannot say anything about parameter $\delta_{2}$ prima facie - it occurs both in numerator and denominator of (23).

\subsection{Sensibility Analysis}

We analyse the sensibility of the model in Table 4, proceeding analogously to Section 2. Results of optimal tax-holidays period correspond to Country 1 and our modifications (first column provides the value for the Cournot equilibrium, the second one for the Stackelberg leadership, the third column shows supranational coordination).

From Table 4 let us comment only the most important findings. The change of FDI externalities has a highly considerable impact on the optimal incentive quantity. On the contrary, the influence of changes in parameters $\alpha_{i}$ and $\beta_{i}$ of the demand 
function appears to be insignificant. More substantial is the influence of $\gamma_{i}$. Increase in $\gamma_{1}$ causes comparatively noticeable fall in incentive duration for all modifications (Cournot, Stackelberg leadership, collusion). Parameter $\gamma_{2}$ works with a lower intensity in the opposite direction.

Table 4.

Sensibility of the Optimal INI Model

\begin{tabular}{|c|c|c|c|c|c|c|c|c|c|c|c|}
\hline $\boldsymbol{Y}_{1}^{\boldsymbol{C}}$ & $\boldsymbol{Y}_{1}^{\boldsymbol{S}}$ & $\boldsymbol{Y}_{1}^{\boldsymbol{K}}$ & $\boldsymbol{\xi}$ & $\boldsymbol{\alpha}_{1}$ & $\boldsymbol{\alpha}_{2}$ & $\boldsymbol{\beta}_{1}$ & $\boldsymbol{\beta}_{2}$ & $\boldsymbol{\gamma}_{1}$ & $\boldsymbol{\gamma}_{2}$ & $\boldsymbol{\tau}_{1}$ & $\boldsymbol{\tau}_{2}$ \\
\hline 7.8 & 8.4 & 6.6 & 400 & 100 & 100 & 50 & 50 & 20 & 20 & 0.24 & 0.19 \\
\hline 11.8 & 12.7 & 9.9 & 600 & 100 & 100 & 50 & 50 & 20 & 20 & 0.24 & 0.19 \\
\hline 0.1 & 0.1 & 0.2 & 10 & 100 & 100 & 50 & 50 & 20 & 20 & 0.24 & 0.19 \\
\hline 10.4 & 11.1 & 9.8 & 400 & 500 & 100 & 50 & 50 & 20 & 20 & 0.24 & 0.19 \\
\hline 7.3 & 7.8 & 5.8 & 400 & 10 & 100 & 50 & 50 & 20 & 20 & 0.24 & 0.19 \\
\hline 6.7 & 7.2 & 3.7 & 400 & 100 & 1,000 & 50 & 50 & 20 & 20 & 0.24 & 0.19 \\
\hline 7.9 & 8.5 & 6.8 & 400 & 100 & 10 & 50 & 50 & 20 & 20 & 0.24 & 0.19 \\
\hline 5.5 & 5.9 & 3.7 & 400 & 100 & 100 & 500 & 50 & 20 & 20 & 0.24 & 0.19 \\
\hline 8.0 & 8.6 & 6.8 & 400 & 100 & 100 & 10 & 50 & 20 & 20 & 0.24 & 0.19 \\
\hline 8.5 & 9.2 & 8.4 & 400 & 100 & 100 & 50 & 500 & 20 & 20 & 0.24 & 0.19 \\
\hline 7.8 & 8.3 & 6.4 & 400 & 100 & 100 & 50 & 10 & 20 & 20 & 0.24 & 0.19 \\
\hline 3.0 & 3.1 & 2.2 & 400 & 100 & 100 & 50 & 50 & 50 & 20 & 0.24 & 0.19 \\
\hline 10.7 & 11.7 & 9.8 & 400 & 100 & 100 & 50 & 50 & 15 & 20 & 0.24 & 0.19 \\
\hline 9.4 & 9.5 & 9.3 & 400 & 100 & 100 & 50 & 50 & 20 & 100 & 0.24 & 0.19 \\
\hline 5.6 & 6.6 & 0.1 & 400 & 100 & 100 & 50 & 50 & 20 & 10 & 0.24 & 0.19 \\
\hline 7.9 & 8.5 & 6.8 & 400 & 100 & 100 & 50 & 50 & 20 & 20 & 0.50 & 0.19 \\
\hline 7.8 & 8.3 & 6.4 & 400 & 100 & 100 & 50 & 50 & 20 & 20 & 0.10 & 0.19 \\
\hline 7.4 & 7.9 & 6.0 & 400 & 100 & 100 & 50 & 50 & 20 & 20 & 0.24 & 0.50 \\
\hline 7.9 & 8.5 & 6.7 & 400 & 100 & 100 & 50 & 50 & 20 & 20 & 0.24 & 0.10 \\
\hline
\end{tabular}

Source: author's computations in accordance to (18), (20) and (23).

\subsection{Limitations \& Extensions}

Determining the costs of tax holidays, we started from Wells et al. (2001), who remind that a lost tax income is not the only expense. An important issue is the latent form of other costs, hard to be researched and separated into a longer period, i.e. difficult to quantify. If we admitted that such "lateral" costs could reach significant values, the model would have to be modified broadly.

The model has also another limitation - it would be interesting to loose the assumption of equivalent spillover values for both countries and study how the changes in different levels of spillovers influence the result. Furthermore, the equal level of $I^{0}$ - investments that flow into the country independently of the provision of INIs - is required for both countries. Parameter of investment rate of return $J$ 
approximates $\pi_{i} / F$ from the first model. Initial Assumption 10 is again restrictive nevertheless a simple solution with different values of $J_{\mathrm{i}}$ is possible.

Finally, (12) does not cover all the parameters, which can influence investor's "willingness to pay" for INIs. It can include the price of labour, its qualification, macroeconomic or political stability, etc.; lots of FDI determinants can be envisioned here.

Also the simplification hidden in Assumption 11 is very significant - the country has to provide each foreign investor with equivalent INI. We do not consider negotiations between the MNC and governments that race in offering INIs to attract investments - which is perhaps a relatively frequent phenomenon (see Oman, 2000; Charlton, 2003). However, our assumption is justifiable because we model fiscal incentives, particularly tax holidays - and because the legislation in taxation field changes difficultly and relatively slowly in democratic countries, fiscal INIs use to be provided via generic schemes (see OECD, 2003).

It is useful to indicate what consequences an embodiment of negotiations between the investor and involved countries during the decision-making process would bring to the previous model (in other words, governments can decide ad hoc and offer incentives tailored to the needs of the MNC). Besides, if we suppose that governments know their own minimal sufficient INI, we can illustrate the interaction between both models. The summary is depicted in Figure 1.

\section{Figure 1}

The General Model of INIs' Supply

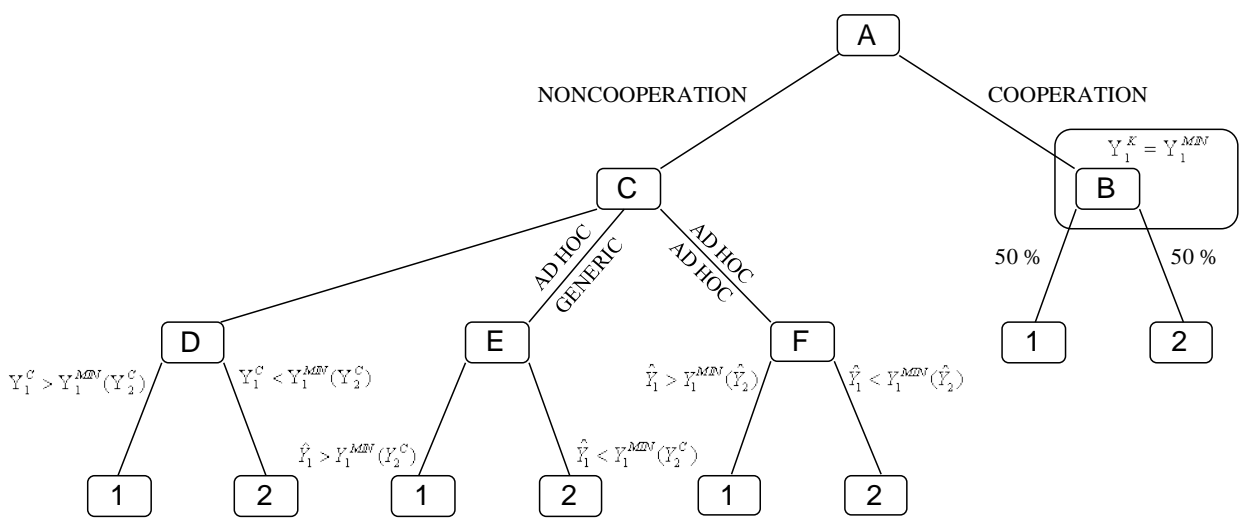

Source: author's scheme on the basis of the presented models.

Status quo (situation without INIs) is disrupted by some external factors in nodal point A. If both countries choose cooperation, they get to point B - a situation of "collusion" from our model, which satisfies the optimal INI supply $Y_{1}^{K}$ for Country 1. Let us label $Y_{1}^{M I N}\left(Y_{2}^{K}\right)$ as the value of minimal sufficient incentive, which corresponds to the given INI of the second country. If $Y_{1}^{K}>Y_{1}^{M I N}\left(Y_{2}^{K}\right)$, Country 1 will succeed in investment allurement. If the equality sets in, investor will be indifferent between both countries (incentive parity). 
Proposition 10. Unsustainability Any collusion agreement can hold neither one round if $Y_{1}^{K}=Y_{1}^{M I N}\left(Y_{2}^{K}\right)$ does not stand.

Proof. No country will willingly abandon all the chances to get FDI (if one does not think about any kind of compensation). For more long-term stability, INIs of both countries will be equal to their minimal sufficient INI. ${ }^{9}$

If countries do not cooperate, they will reach point C. Now each country sets whether to provide generic or ad hoc INIs. If both countries decide for the first possibility, they meet in point $\mathrm{D}$ - the situation modelled by the Cournot competition. Country 1 gains the investment if $Y_{1}^{C}>Y_{1}^{M I N}\left(Y_{2}^{C}\right)$.

Let Country 1 decide to offer INIs ad hoc, while Country 2 still uses a generic scheme (point E).

Proposition 11. Expected utility of Country 1 in point $E$ is higher or equal to its expected utility in point D.

Proof. Country 1 has an evident strategic advantage: if $Y_{1}^{C}>Y_{1}^{M I N}\left(Y_{2}^{C}\right)$, it decreases $Y_{1}$ close to $Y_{1}^{M I N}\left(Y_{2}^{C}\right)$, but can still offer more convenient conditions to investors. The MNC then chooses Country 1, which will moreover get better, compared to the Cournot equilibrium. If $Y_{1}^{C} \leq Y_{1}^{M I N}\left(Y_{2}^{C}\right)$, Country 1 still has a chance of attracting the investment. It identifies such a level of provided INIs by which its total utility from transaction is equal to zero (marked as $\hat{Y}_{1}$ ) and is willing to increase $Y_{1}$ until this point and gains the investment if $\hat{Y}_{1}>Y_{1}^{M I N}\left(Y_{2}^{C}\right)$.

The last possibility is that both countries provide INIs ad hoc (point F). For each country individually it is optimal to select such a $Y$, which will slightly exceed its minimal sufficient incentive and so will attract investment with the smallest costs possible. This process of action and reaction ends right in the point where at least one country provides INIs for which $Y_{i}=\hat{Y}_{i}$. If also $\hat{Y}_{i}<Y_{i}^{M I N}\left(\hat{Y}_{j}\right)$, country $i$ loses investment for the benefit of country $j$, which will have positive utility from the whole transaction.

Proposition 12. Competition efficiency If $Y_{i}=\hat{Y}_{i}$ as well as $\hat{Y}_{i}=Y_{i}^{M I N}\left(\hat{Y}_{j}\right)$ hold, perfect spillover internalization follows.

Proof. It comes to incentive parity; the investor is indifferent between both countries and the winner has zero utility from the transaction. The benefit is fully taken away by the investor because each country bids up to the spillover value.

Figure 1 also indicates that apart from the classical dilemma of cooperation and noncooperation, another problem in the decision-making field of the government can exist, which can have the nature of the prisoner's dilemma. Each country hungers for being Country 1 in point $\mathrm{E}$ - where it has broader margin of maneuvre, since the second country is not flexible. If both countries strive for this flexibility and offer INIs ad hoc (point F), apparently they will suffer in comparison to the situation of

9 Realize that $Y_{1}=Y_{1}^{M I N}\left(Y_{2}\right)$ can be valid if and only if $Y_{2}=Y_{2}^{M I N}\left(Y_{1}\right)$. What is more, naturally $Y_{1}>Y_{1}^{M I N}\left(Y_{2}\right)$ can hold if and only if $Y_{2}<Y_{2}^{M I N}\left(Y_{1}\right)$. 
generic provision (point D). In general, the winner will have to offer a substantially higher incentive. ${ }^{10}$

Point $F$ represents (the only one) stable Nash equilibrium of the game because for none of the countries it pays off to deviate unilaterally from the strategy heading to $\mathrm{F}$. It implies that we should observe FDI competition "using all weapons", i.e., escalation of supplied incentives until the last competitor fails. However, ad hoc application of INIs is often regulated. For example, Besley, Seabright (1999) discuss restrictions of ad hoc incentives in the EU.

This implies that point $\mathrm{D}$ can be instead of $\mathrm{F}$ the equilibrium for country competing inside the EU - point B is still not accessible because of the prisoner's dilemma, points $\mathrm{E}$ and $\mathrm{F}$ are inaccessible because of regulation. While in point $\mathrm{D}$ countries provide Cournot INIs, in point F supplied INIs are close or equal to countries' minimal sufficient INIs.

\section{Conclusion}

The main aim of this paper is to contribute to a better comprehension of the inward foreign direct investment incentives (INIs) phenomena by studying their determinants. We introduced two simple microeconomic models, each one dealing with a different specification of the problem, and used them as tools for describing the foreign direct investment policy-making.

The Minimal Sufficient INI Model, based on the profit parity, is solved primarily from the point of view of a foreign investor - the government's task is only to set such a level of INIs which does not threaten its relative competitiveness with respect to a rival country. We have deduced that toward the equilibrium level of incentives, both country's corporate income tax (CIT) rate and the generosity of incentive systems of its rival countries have a principal influence. Market size plays an important part as well.

The Optimal INI Model was tackled from the point of view of a government maximizing public utility. The basis of the model lies in the application of the classical models of oligopoly (Cournot, Stackelberg) to the situation of subsidy competition. The most important conclusions include as the significance of spillovers for explanation of the optimal level of INIs, so the ambiguous influence of the CIT rate. We show that possible supranational coordination of incentives can either decrease or increase the supply of such subsidies, depending mainly on assumed spillover value. Thus, using a different methodology, we support the result of Haufler, Wooton (2006).

Free competition between producers of INIs will lead to stimuli schemes of the Minimal Sufficient INI Model. On the contrary, if their supply is regulated (e.g., by prohibition of ad hoc incentives), the equilibrium level corresponds to the Optimal

10 Notice that movement from point $\mathrm{D}$ to point $\mathrm{F}$ can eventually pay off only to country $i$. Its Cournot level of INIs must be under the minimum sufficient INI in point D, but moreover $\hat{Y}_{i}>Y_{i}^{M I N}\left(\hat{Y}_{j}\right)$ must hold. Only in case when $Y_{1}^{C}=Y_{1}^{M I N}\left(Y_{2}^{C}\right) \& \hat{Y}_{1}=Y_{1}^{M I N}\left(\hat{Y}_{2}\right)$, we have the pure prisoner's dilemma. 
INI Model. This implies that on the background of the regulation of INIs, the host country's CIT rate does not have to represent a significant determinant of the provision of INIs.

Our results are sensitive to the assumed type of competition, which is equivalent to the usage of the Cournot model. But the framework (in a nutshell, formalizing INI as a commodity) is general enough to apply other models of oligopoly - starting, e.g., with the Bertrand model. It would not be difficult to allow for some broader differences between the studied countries (i.e., relaxing Assumption 10), as well as for non-linear investors' demands in the CIT rate, modifying the definition of inverse demand functions in (12). It is also possible to extend the analysis to more than only 2 countries. Such modifications are left for further research.

\section{References}

Barros, P. P., Cabral, L. (2000), "Competing for Foreign Direct Investment." Review of International Economics, 8(2), pp. 360-71.

Besley, T., Seabright, P. (1999), "The Effects and Policy Implications of State Aids to Industry: An Economic Analysis." Economic Policy, 14(28), pp. 13-53.

Bjorvatn, K., Eckel, C. (2006), "Policy Competition for Foreign Direct Investment between Asymmetric Countries." European Economic Review, 50(7), pp. 1891-1907.

Blomstrom, M., Kokko, A. (2003), "The Economics of Foreign Direct Investment Incentives." National Bureau of Economic Research, Inc., NBER Working Papers 9489.

Charlton, A. (2003), "Incentive Bidding for Mobile Investment: Economic Consequences and Potential Responses." OECD Development Centre, Working Paper 203.

Devereux, M. (2006), "Tax Competition: Theory and Empirical Evidence." Centre for Business Taxation, Oxford University, mimeo.

Gola, P. (2006), "Mzdy ve východní Evropě pod lupou." Měšec. Available (in Czech) at www.mesec.cz/clanky/mzdy-ve-vychodni-evrope-pod-lupou.

Görg, H., Strobl, E. (2001), "Multinational Companies and Productivity Spillovers: A MetaAnalysis." The Economic Journal 111(475), pp. 723-739.

Haaland, J. I., Wooton, I. (1999), "International Competition for Multinational Investment. Scandinavian Journal of Economics, 101(4), pp. 631-49.

Haaparanta, P. (1996), "Competition for Foreign Direct Investment." Journal of Public Economics 63(1), pp. 141-53.

Haufler, A., Wooton, I. (1999), "Country Size and Tax Competition for Foreign Direct Investment." Journal of Public Economics, 71(1), pp. 121-139.

Haufler, A., Wooton, I. (2006), "The Effects of Regional Tax and Subsidy Coordination on Foreign Direct Investment." European Economic Review, 50(2), pp. 285-305.

Havránek, T., Iršová, Z. (2008), "Intra-Industry Spillovers from Inward FDI: A Meta-Regression Analysis." Charles University Prague, Faculty of Social Sciences, Institute of Economic Studies. Working Papers IES 2008/08.

IMF (2006): World Economic Outlook. September 2006, downloaded on 15/10/2006. Available at: www.imf.org/external/ns/cs.aspx?id=29.

Ma, J. (2007), "Double-Edged Incentive Competition for Foreign Direct Investment." Ph.D. thesis, Peking University.

Meyer, K. E., Sinani, E. (2005), "Spillovers from Foreign Direct Investment: A Meta Analysis." Center for East European Studies. Working paper No. 59. 
da Motta Veiga, P., Iglesias, R. (1998), "Policy Competition and Foreign Direct Investment in Brazil." Technical Report, OECD.

NEWTON (2003), FDI Incentives and Their Efficiency. Macroeconomic Analysis 1/2003, NEWTON. Available at: www.newton.cz/analyzy.

OECD (2003), Checklist for Foreign Direct Investment Incentive Policies. Technical Report, OECD.

Oman, C. (2000), "Policy Competition for Foreign Direct Investment: A Study of Competition Among Governments to Attract FDI." Paris: OECD Development Centre.

Pennings, E. (2001), "How to Maximize Domestic Benefits from Irreversible Foreign Investments." Innocenzo Gasparini Institute for Economic Research, Bocconi University. Working Paper 205.

SAO (2006), "Management of the State Budget Funds Spent for Providing of Investment Incentives and Investment Aids on the Basis of 'Memorandum of Understanding Declaring Common Intention'." Technical report, Supreme Audit Office of the Czech Republic.

Sedmihradský, M. (2002), "Daňové zatížení jako konkurenční faktor v mezinárodní soutěži." Czech Journal of Economics and Finance, 52, pp. 550-565. (In Czech).

Sieh Lee, M. L. (1998), "Competing for Foreign Direct Investment: The Case of Malaysia." Technical report, OECD, mimeo.

UNCTAD (1996), Incentives and Foreign Direct Investment. New York: United Nations.

Wells, L. T., Allen, N., Morisset, J., Pirnia, N. (2001), Using Tax Incentives to Compete for Foreign Investment: Are They Worth the Cost? Washington, DC: FIAS.

Wooster, R. B., Diebel, D. S. (2006), "Productivity Spillovers from Foreign Direct Investment in Developing Countries: A Meta-Regression Analysis." Working Paper series, SSRN. Available at: http://ssrn.com/abstract=898400 